\title{
Toxicology and efficacy of tumor-targeting Salmonella typhimurium A1-R compared to VNP 20009 in a syngeneic mouse tumor model in immunocompetent mice
}

\author{
Yong Zhang ${ }^{1}$, Wenluo Cao $^{1,2}$, Makoto Toneri ${ }^{1,2}$, Nan Zhang ${ }^{1}$, Tasuku Kiyuna ${ }^{1,2}$, \\ Takashi Murakami ${ }^{1,2}$, Scott D. Nelson ${ }^{3}$, Sarah M. Dry ${ }^{3}$, Yunfeng Li ${ }^{3}$, Shukuan Li ${ }^{1}$, \\ Xiaoen Wang ${ }^{1}$, Huaiyu Ma ${ }^{1}$, Arun S. Singh ${ }^{4}$, Fritz C. Eilber ${ }^{5}$, Robert M. Hoffman ${ }^{1,2}$ \\ and Ming Zhao ${ }^{1}$ \\ ${ }^{1}$ AntiCancer, Inc., San Diego, California, USA \\ ${ }^{2}$ Department of Surgery, University of California, San Diego, California, USA \\ ${ }^{3}$ Department of Pathology, University of California, Los Angeles, California, USA \\ ${ }^{4}$ Department of Hematology/Oncology, University of California, Los Angeles, California, USA \\ ${ }^{5}$ Division of Surgical Oncology, University of California, Los Angeles, California, USA \\ Correspondence to: Ming Zhao, email: all@anticancer.com \\ Fritz C. Eilber, email: fceilber@mednet.ucla.edu \\ Keywords: Salmonella typhimurium A 1-R, VNP20009, toxicity, tumor targeting, biodistribution \\ Received: March 01, $2017 \quad$ Accepted:March 21, $2017 \quad$ Published: May 03, 2017 \\ Copyright: Zhang et al. This is an open-access article distributed under the terms of the Creative Commons Attribution License 3.0 \\ (CC BY 3.0), which permits unrestricted use, distribution, and reproduction in any medium, provided the original author and source \\ are credited.
}

\section{ABSTRACT}

Salmonella typhimurium A1-R (S. typhimurium A1-R) attenuated by leu and arg auxotrophy has been shown to target multiple types of cancer in mouse models. In the present study, toxicologic and biodistribution studies of tumor-targeting $S$. typhimurium A1-R and S. typhimurium VNP20009 (VNP 20009) were performed in a syngeneic tumor model growing in immunocompetent BALB/c mice. Single or multiple doses of S. typhimurium A1-R of $2.5 \times 10^{5}$ and $5 \times 10^{5}$ were tolerated. A single dose of $1 \times 10^{6}$ resulted in mouse death. S. typhimurium A1-R ( $\left.5 \times 10^{5} \mathrm{CFU}\right)$ was eliminated from the circulation, liver and spleen approximately 3-5 days after bacterial administration via the tail vein, but remained in the tumor in high amounts. S. typhimurium A1-R was cleared from other organs much more rapidly. S. typhimurium A1-R and VNP 20009 toxicity to the spleen and liver was minimal. S. typhimurium A1-R showed higher selective targeting to the necrotic areas of the tumors than VNP20009. S. typhimurium A1-R inhibited the growth of CT26 colon carcinoma to a greater extent at the same dose of VNP20009. In conclusion, we have determined a safe dose and schedule of $S$. typhimurium A1-R administration in BALB/c mice, which is also efficacious against tumor growth. The results of the present report indicate similar toxicity of $S$. typhimurium A1-R and VNP20009, but greater antitumor efficacy of S. typhimurium A1-R in an immunocompetent animal. Since VNP2009 has already proven safe in a Phase I clinical trial, the present results indicate the high clinical potential of S. typhimurium A1-R.

\section{INTRODUCTION}

For more than 200 years, there have been reports that cancer patients went into remission after recovering from bacterial infections [1]. From the late 19th to early 20th century, William Coley, an American physician, treated cancer patients with both live and heat-killed bacteria such as Streptococcus pyogenes and Serratia marcescens as firstline therapy for sarcoma and lymphoma. The combination of Coley's heat-killed bacteria was referred to as "Coley's toxins, which remained in clinical use for sarcoma patients until 1963 [1]. Since 1976, BCG (Bacillus Calmette-Guerin) 
bacteria have been used to treat superficial bladder cancer [2], which is still in clinical use [3].

There has been a great resurgence in preclinical research on bacterial therapy of cancer in the last 20 years [4]. Salmonella species are the most extensively studied bacteria in the field of tumor targeting. They are Gramnegative facultative-anaerobic bacteria that can grow and replicate inside host cells. Some Salmonella strains can preferentially colonize solid tumors [5-8].

Salmonella typhimurium VNP20009 (VNP20009) is attenuated with a lipid $\mathrm{A}$-mutation $(m s b B)$, purine auxotrophy (purl) and amino acid autotrophy [9]. In a Phase I clinical trial on patients with metastatic melanoma and renal-cell carcinoma in the United States, VNP20009 was not toxic but poorly colonized the patients' tumors, perhaps because it was over attenuated [10]. At the highest tolerated dose, some tumor colonization was observed [10].

Another strain of $S$. typhimurium A1-R, auxotrophic for leu-arg has been developed by our laboratory. $S$. typhimurium A1-R was effective against primary and metastatic tumors as monotherapy in nude mouse models of major cancers, including prostate $[8,11]$, breast $[12$ $14]$, lung $[15,16]$, pancreatic $[17-21]$, ovarian $[22,23]$ stomach [24], and cervical cancer [25]. In addition, $S$. typhimurium A1-R was effective against patient-derived orthotopic models (PDOX) of pancreatic cancer $[17,21]$, sarcoma [26-28] and melanoma [29-32].

Tumors with a high degree of vascularity were more sensitive to $S$. typhimurium A1-R, and vascular destruction appears to play a role in S. typhimurium A1-R antitumor efficacy [16].

In the present report, we compare efficacy, tumor targeting and toxicity of $S$. typhimurium A1-R and VNP20009, since VNP20009 has been tested to be safe in a Phase I clinical trial [10].

\section{RESULTS AND DISCUSSION}

\section{Correlation between optical sensitivity and colony counting to quantitate bacteria}

In order to determine viable bacterial counts, we analyzed the relationship between the $\mathrm{OD}_{600}$ value and bacteria colony forming units (CFU) on LB agar. A linear relationship between $\mathrm{OD}_{600}$ and $\mathrm{CFU}$ was observed for $S$. typhimurium A1-R: $\mathrm{Y}=20.141 \mathrm{x}+2.0578, \mathrm{R}^{2}=0.9473$ ) (Figure 1).

\section{Effect of a single-dose $S$. typhimurium A1-R on body weight of non-tumor-bearing BALB/c mice}

Six- to 8-week-old BALB/c mice without tumors, with an average body weight 20 to 22 gram, were used in the study. A single-dose of $S$. typhimurium A1-R at $1 \times 10^{5}$ $-5 \times 10^{5} \mathrm{CFU} / \mathrm{mouse}$ was administred i.v. Acute weight loss of $10 \%$ to $20 \%$ from day 0 was observed in all cohorts. However, body weight began recover by day 6 . However, $1 \times 10^{6} \mathrm{CFU} / \mathrm{mouse}$ did cause severe weight loss (Figure 2A, 2B). No signs of delayed toxicity were observed. $S$. typhimurium A1-R doses at $1 \times 10^{5}$ and $5 \times 10^{5} \mathrm{CFU}$ did not cause mouse death, but $1 \times 10^{6} \mathrm{CFU}$ did (Figure 2C, 2D).

\section{Effect of a single dose of $S$. typhimurium A1-R on body weight of tumor-bearing $B A L B / C$ mice}

Single doses of $1 \times 10^{5}, 5 \times 10^{5}$ and $1 \times 10^{6}$ were given to $\mathrm{BALB} / \mathrm{c}$ mice bearing subcutaneous CT26 murine colon tumors. The body weight loss in the tumorbearing mice was less than in the normal mice. The tumorbearing mice which were given the $1 \times 10^{6} \mathrm{CFU}$ dose of $S$. typhimurium A1-R rapidly recovered unlike the nontumor bearing mice (Figure 3A, 3B). However, although no deaths were observed at the two lower doses, the $1 \times$ $10^{6} \mathrm{CFU}$ dose caused death (Figure 3C, 3D).

\section{Effect of multiple doses of S. typhimurium A1-R on the body weight of tumor-bearing mice}

Based on the single-dose toxicologic results, we also assessed the toxicity of multiple doses of S. typhimurium A1-R compared with PBS administered to tumor-bearing mice (Figure 4). Weekly doses of S. typhimurium A1-R at 2.5 , or $5 \times 10^{5} \mathrm{CFU} / \mathrm{mouse}$, were administered for 3 weeks. The $2.5 \times 10^{5} \mathrm{CFU}$ weekly doses did not cause noticeable weight loss. The $5 \times 10^{5} \mathrm{CFU} /$ mouse caused a body weight loss by day-4 which was recovered by day11. Weekly doses of VNP20009 at $5 \times 10^{5}$ or $1 \times 10^{6} \mathrm{CFU} /$ mouse were administered for 3 weeks without noticeable weight loss.

\section{Clearance of $S$. typhimurium A1-R from the circulation}

To quantitatively assess the clearance of bacteria from the circulation, GFP-labeled S. typhimurium A1-R (S. typhimurium A1-R-GFP) was intravenously injected into non-tumor-bearing and tumor-bearing BALB/c mice. S. typhimurium A1-R-GFP in the blood was collected, cultured, and counted at various times after injection using three mice per time point. Greater than $95 \%$ of the bacteria were cleared from the circulation within 1 day in non-tumor-bearing mice, and the number of CFU fell to barely detectable levels over the next 7 days (Figure 5). Bacteria in tumor-bearing mice were cleared more slowly (Figure 5).

\section{Biodistribution of bacteria}

To determine the distribution of bacteria, normal and tumor-bearing $\mathrm{BALB} / \mathrm{c}$ mice were injected with S. typhimurium A1-R GFP. Organs and tumors were 


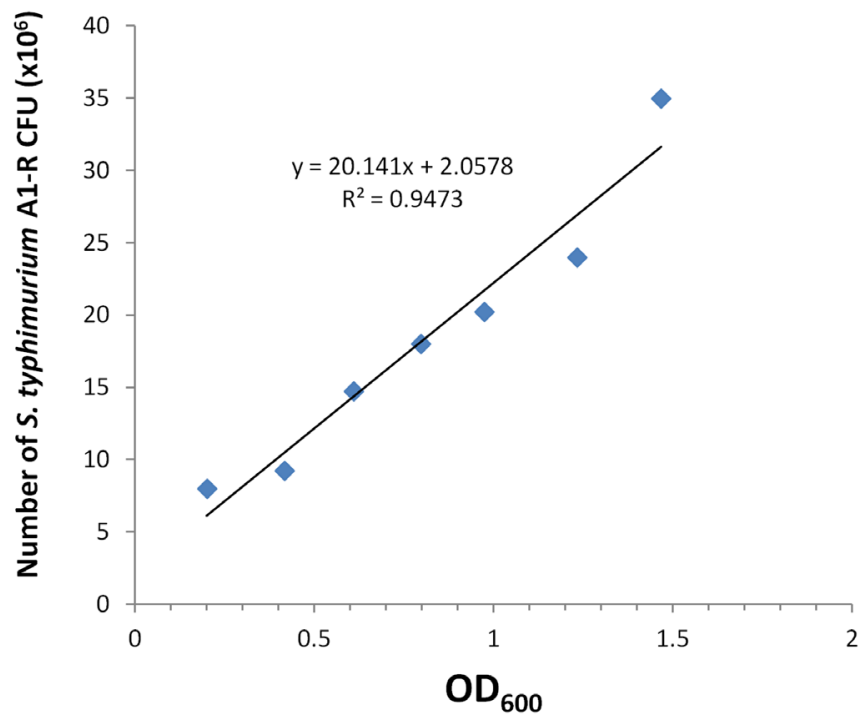

Figure 1: Comparison of OD600 and colony counting to quantify bacteria. GFP-expressing S. typhimurium A1-R-GFP was grown overnight in LB medium and then diluted 1:10 in LB medium. Bacteria were harvested at late-log phase, washed with PBS, and then diluted in PBS. OD ${ }_{600}$ measurements were performed on a spectrophotometer at dilutions of $10 \times$. Each dilution analysis of bacteria in PBS was plated and cultured overnight in LB agar and the number of resulting bacterial colonies was counted. Regression line demonstrates the correlation between colony-forming units with $(\mathrm{CFU})$ bacteria and $\mathrm{OD}_{600}$.

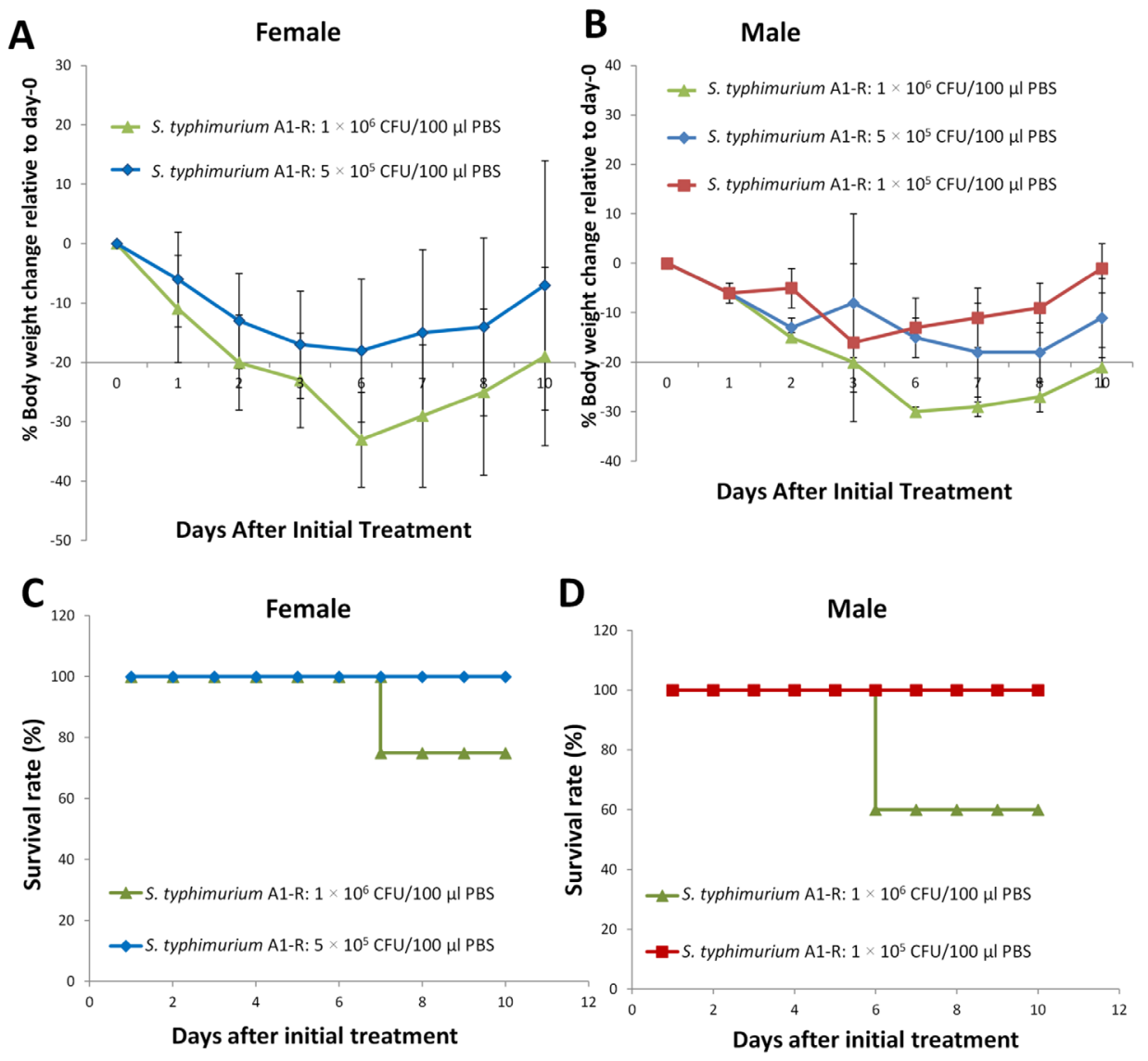

Figure 2: Effect of a single dose of $S$. typhimurium A1-R on body weight of non-tumor-bearing mice. Normal BALB/c mice, aged 6 weeks, were injected with $S$. typhimurium A1-R at different doses in $100 \mu$ PBS into the tail vein. Body weight was measured using an electronic scale. (A) Body weight curve for male female $(n=5)$. (B) Body weight curve for male mice. $n=5$ mice for each group. (C) Survival time curve for female mice $(\mathrm{n}=5)$. (D) Survival time curve for male mice. $\mathrm{n}=5$ mice for each group. 


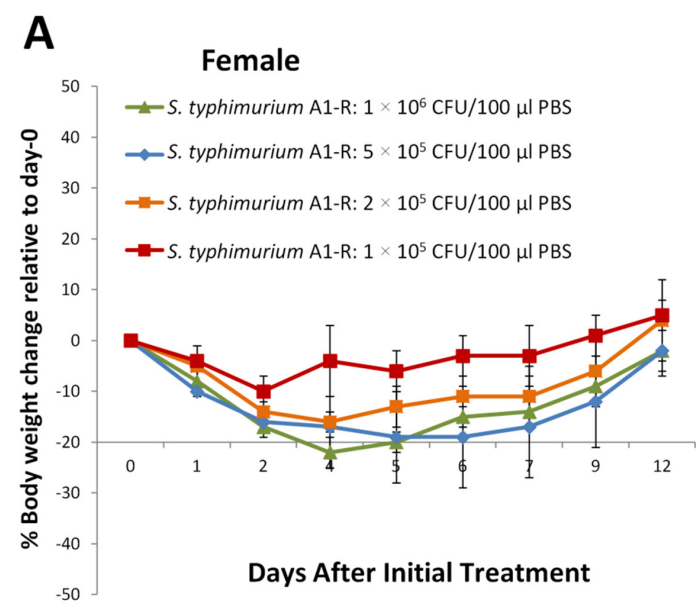

B Male
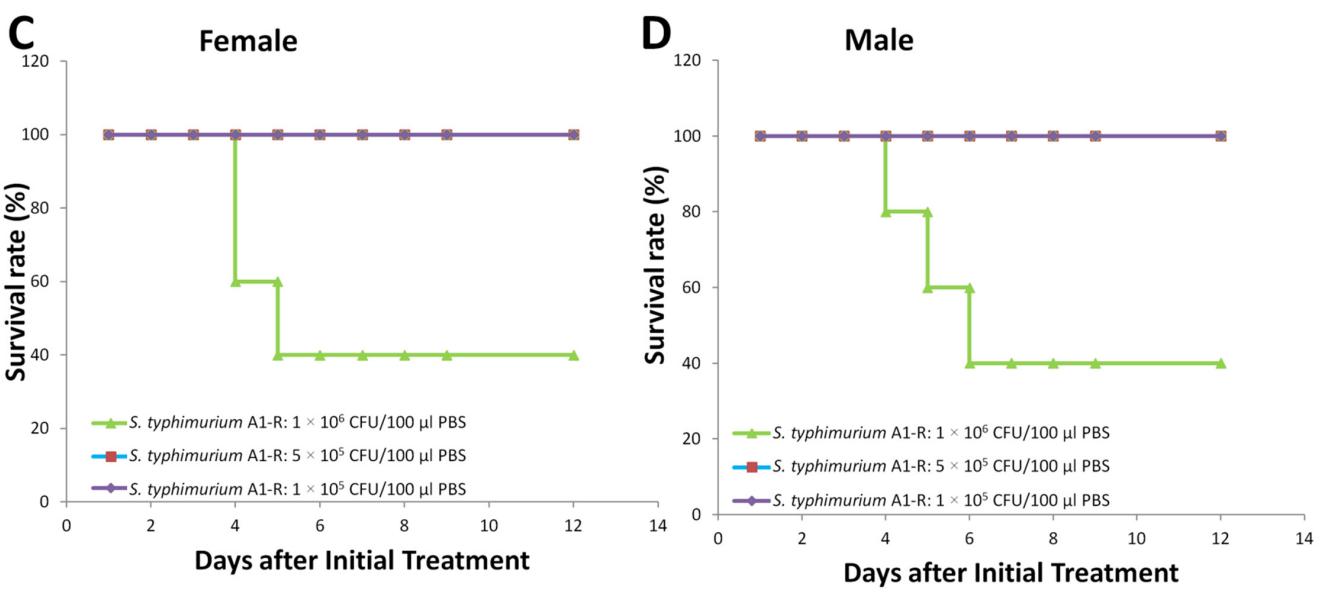

Figure 3: Effect of a single dose of $S$. typhimurium A1-R on body weight of tumor-bearing mice. BALB/c mice bearing CT26 tumors with a tumor volume of $100 \mathrm{~mm}^{3}$ were treated with $S$. typhimurium A1-R at different doses in $100 \mu 1$ PBS into the tail vein. Body weight was measured using an electronic scale. (A) Body weight curve for female mice $(\mathrm{n}=5)$. (B) Body weight curve for male mice. $n=5$ mice for each group. (C) Survival curve for female mice $(n=5)$. (D) Survival curve for male mice. $n=5$ mice for each group.

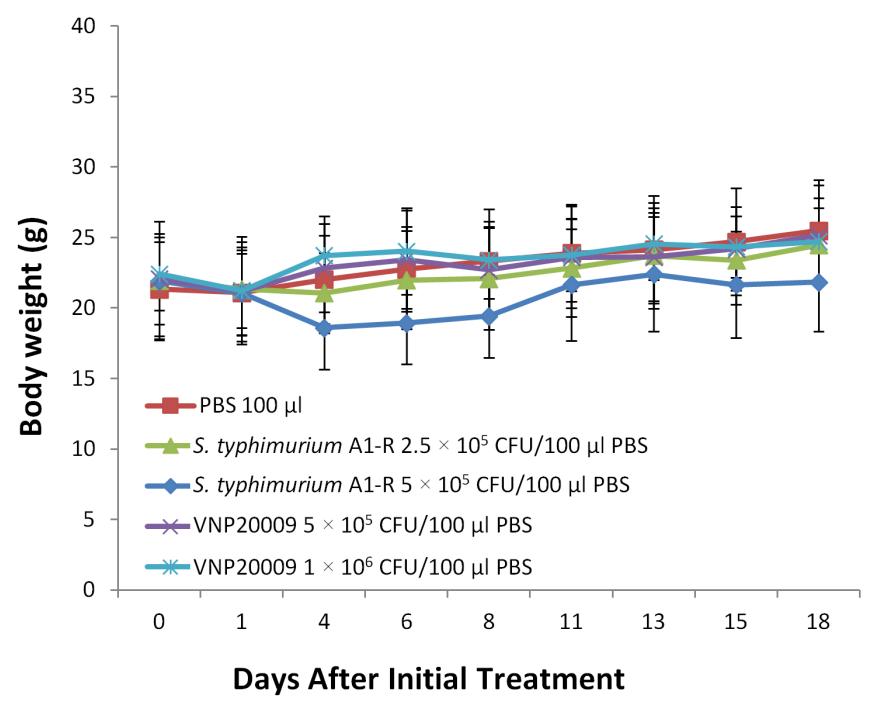

Figure 4: Effect of multiple doses of $S$. typhimurium A1-R and $S$. typhimurium VNP20009 on body weight of tumorbearing mice. Mice were treated with $2.5 \times 10^{5} \mathrm{CFU}$, and $5 \times 10^{5} \mathrm{CFU}$ S. typhimurium A1-R weekly or $5 \times 10^{5}$ and $1 \times 10^{6} \mathrm{CFU}$ VNP20009 weekly $\times 3$. All treatments were administered i.v. 
collected, homogenized and S. typhimurium A1-R was cultured on LB agar. The number of CFU was counted from organs starting 1 hour after injection. Bacteria colonies from organs and tumors were subsequently observed by fluorescence microscopy. In non-tumorbearing mice, significant $S$. typhimurium A1-R-GFP colonies from organs were present at $1 \mathrm{~h}$ after injection, but were undetectable 1week later. The largest amount of S. typhimurium A1-R-GFP was present in the liver and spleen, but was cleared by 7 days. The other organs were cleared by 3 days (Figure 6A).

In the tumor-bearing mice, $S$. typhimurium A1-RGFP in tumors survived much longer than in the normal organs (Figure 6B).

S. typhimurium A1-R-GFP and VNP20009-RFP were isolated from the viable and necrotic tumor regions and cultured in LB agar. S. typhimurium A1-R survived in tumor necrotic regions more than VNP20009 at day-7 when the bacteria were administered i.v. $(p<0.01)$ (Figure 7). FP Fluorescent colonies of S. typhimurium A1-R-GFP isolated from the tumor, spleen and liver at various time points were imaged.

Fluorescent colonies are seen derived from the tumor at all time points from 1 hour to day 7 . Fluorescent colonies can be seen isolated from the liver and spleen only at 1 hours and day 1 and not at day 3 and day 7 (Figure 8).

\section{Effect of S. typhimurium A1-R on organ weight and histology}

Each mouse received a single intravenous injection of $S$. typhimurium A1-R $\left(5 \times 10^{5} \mathrm{CFU}\right)$. In non-tumorbearing mice, only the spleen significantly increased in weight after treatment with $S$. typhimurium A1-R $\left(5 \times 10^{5}\right.$ CFU) beginning at day 3 (Figure 9A).

In female $\mathrm{BALB} / \mathrm{c}$ mice bearing subcutaneous CT26 mouse colon tumors, S. typhimurium A1-R (5 $\left.\times 10^{5} \mathrm{CFU}\right)$ treatment also caused the spleen to gain significant weight beginning at day 7 , compared to control mice (Figure 9B).

Histopathologic analysis of liver and spleen at day 3 post-treatment of $S$. typhimurium A1-R or VNP20009 showed pathological changes in both organs (Figure 9C).

\section{Efficacy of $S$. typhimurium A1-R and VNP20009 on the CT26 colon tumor in $B A L B / c$ mice}

$S$. typhimurium A1-R reduced tumor growth to a greater extent than VNP20009 $(p<0.05)$. S. typhimurium A1-R at $5 \times 10^{5} \mathrm{CFU}$ arrested tumor growth. VNP20009 at $1 \times 10^{6} \mathrm{CFU}$ and S. typhimurium A1-R at $2.5 \times 10^{5} \mathrm{CFU}$ both slowed tumor growth to a similar extent, but could

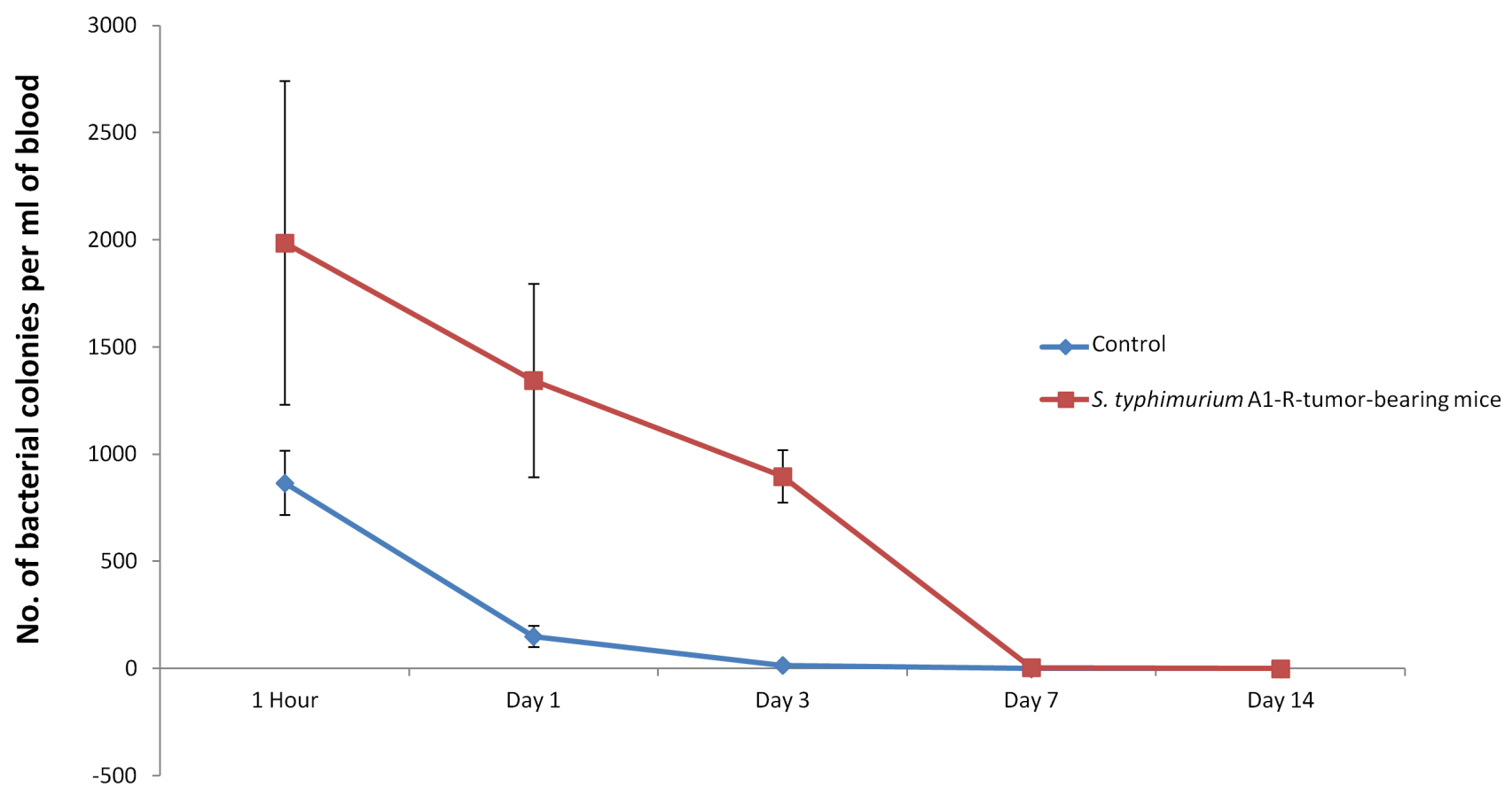

Days after Initial Treatment

Figure 5: Bacteria clearance from blood circulation. S. typhimurium A1-R $\left(5 \times 10^{5} \mathrm{CFU} / 100 \mu \mathrm{PBS} / \mathrm{mouse}\right)$ were injected into non-tumor-bearing mice or CT26 tumor-bearing BALB/c mice. Bacteria in $100 \mu \mathrm{l}$ of blood were counted after overnight culture in LB agar. Values in both graphs represent the mean (with standard deviation) of at least three mice per time point. 


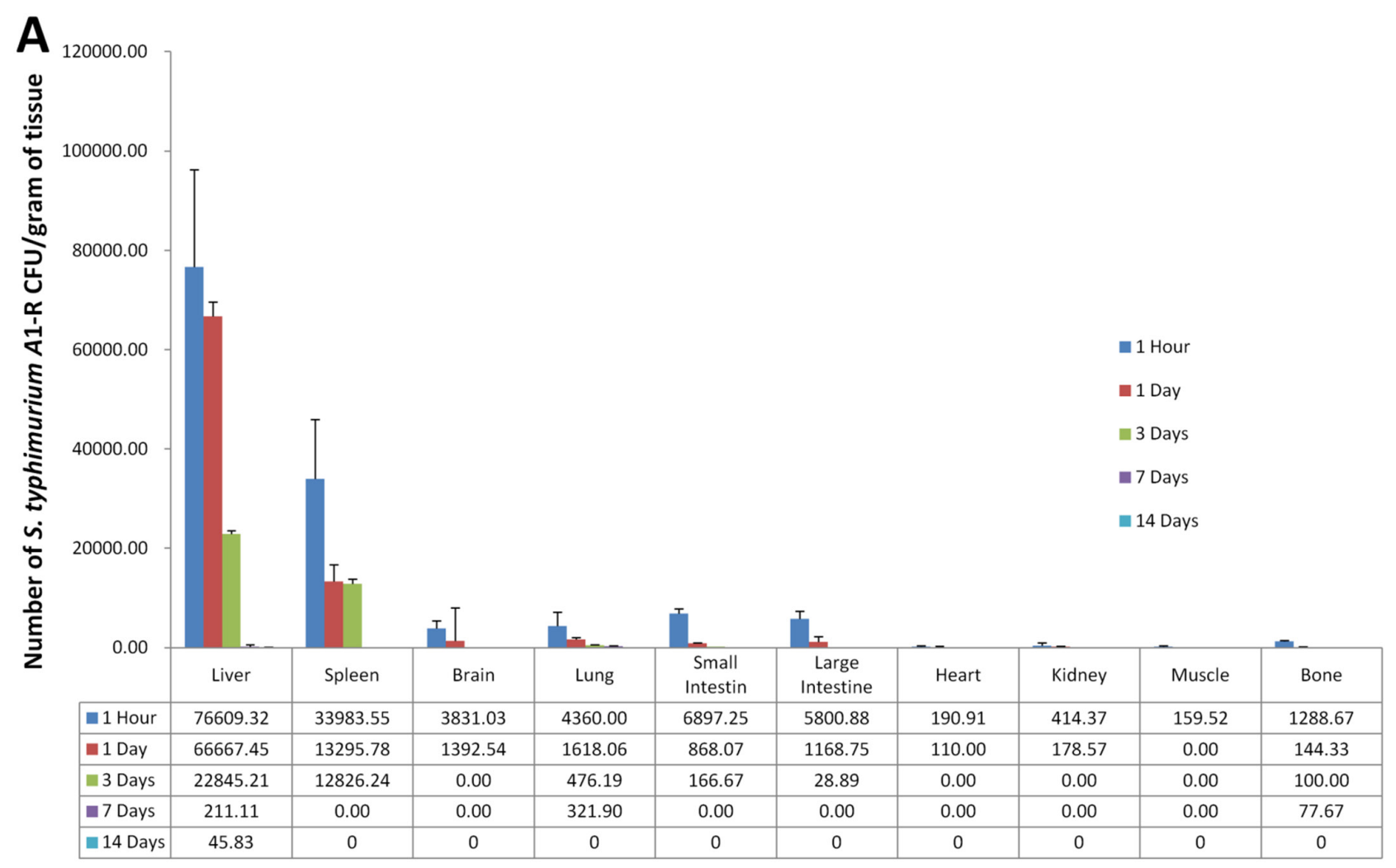

B

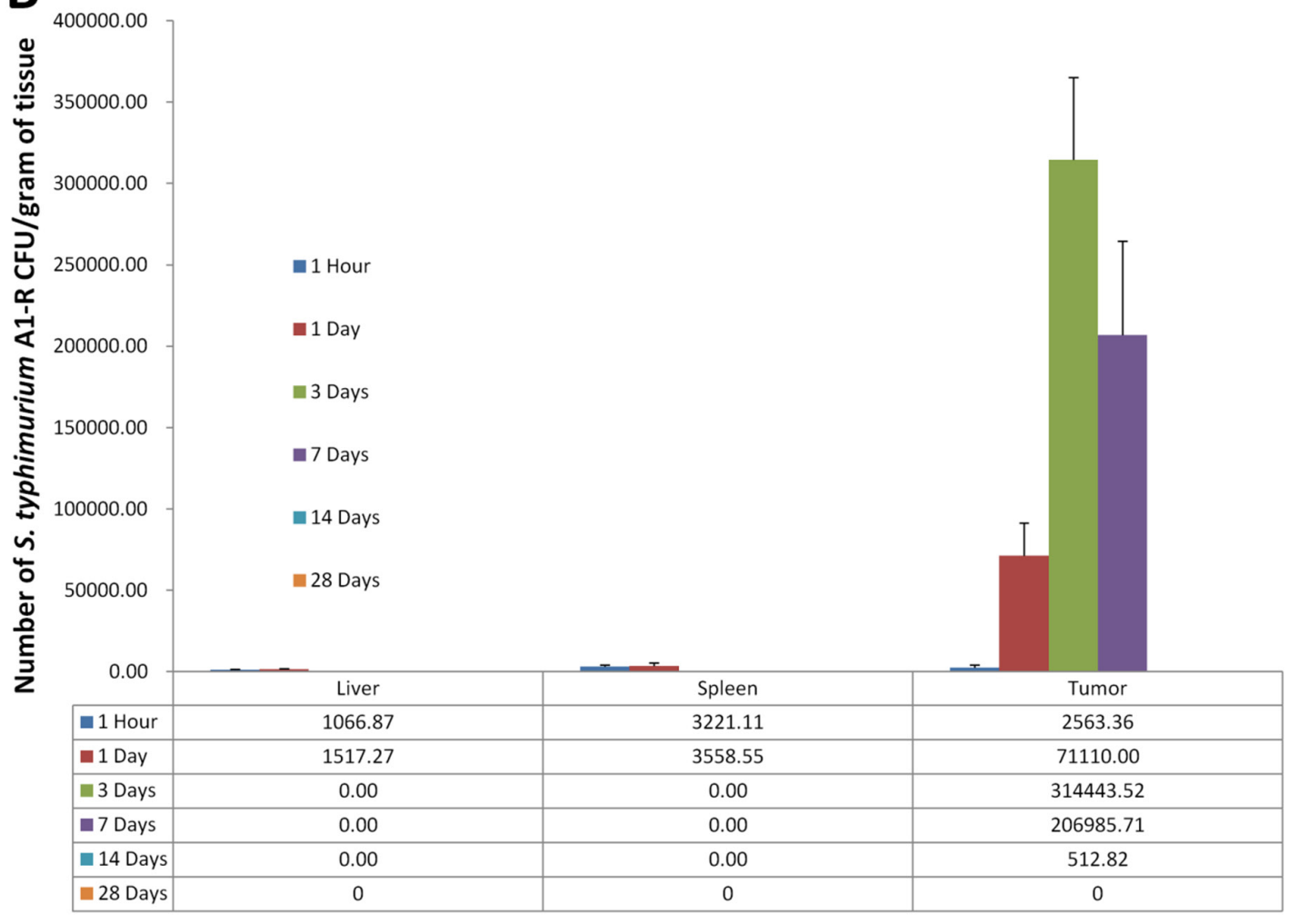

Figure 6: Distribution of $\boldsymbol{S}$. typhimurium A1-R. S. typhimurium A1-R $\left(5 \times 10^{5} \mathrm{CFU} / 100 \mu 1 \mathrm{PBS} /\right.$ mouse $)$ were injected into normal (A) or CT26 tumor-bearing BALB/c mice (B). Tissues were removed at time points indicated and homogenized. Homogenates from isolated from the tumors and organs were cultured in LB agar. At least three mice were evaluated per time point. 


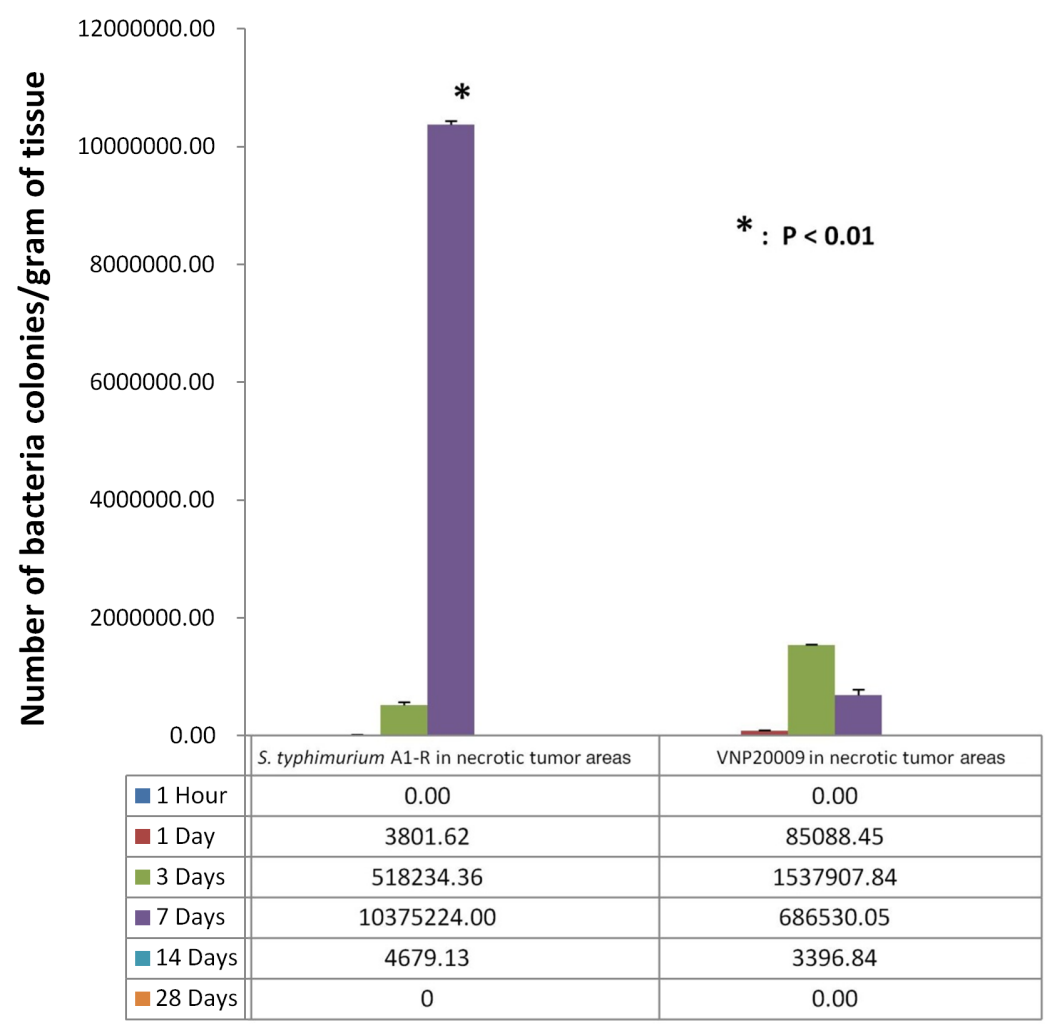

Figure 7: S. typhimurium A1-R and VNP20009 were isolated from the necrotic areas of tumors at various time points.

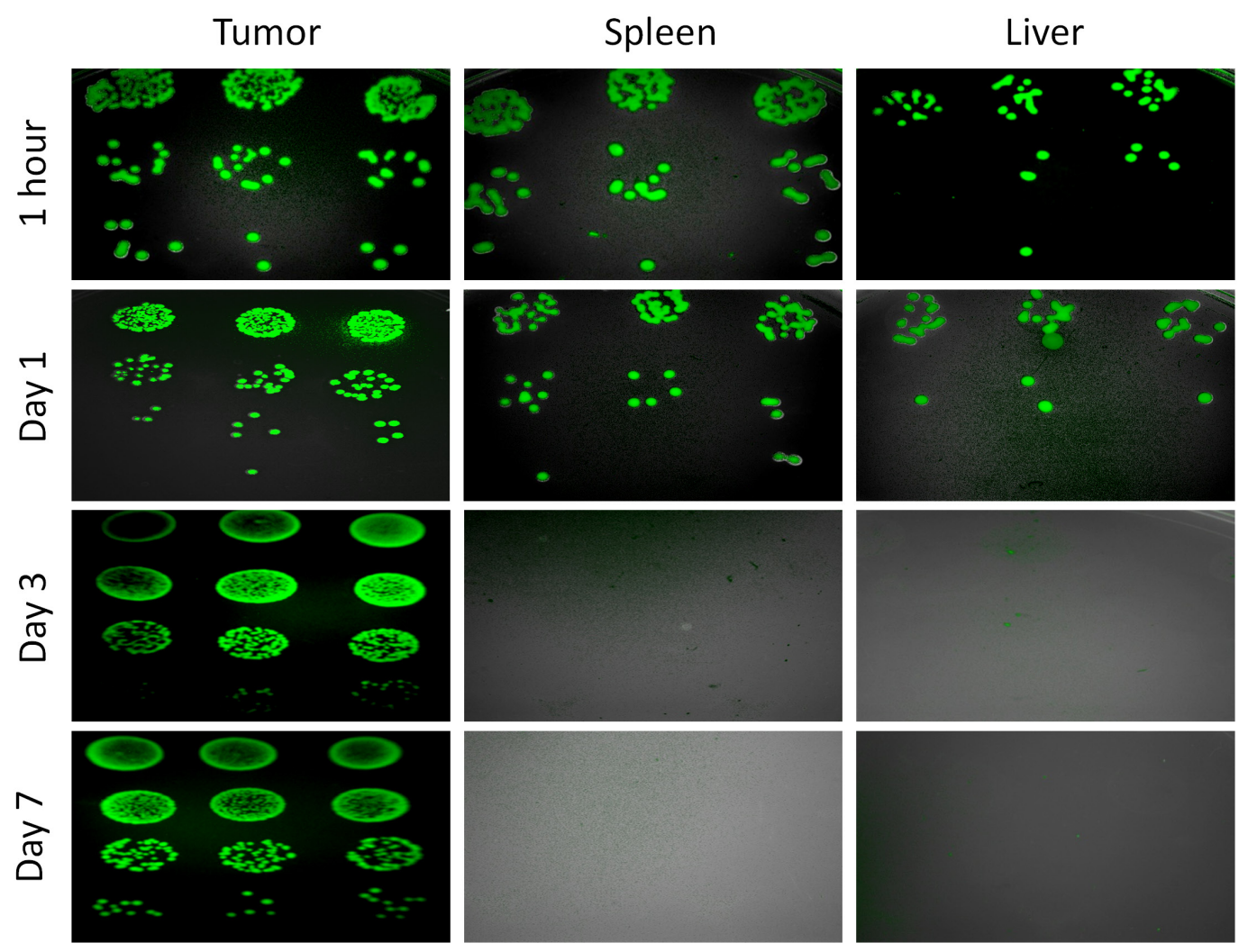

Figure 8: Fluorescence images of $S$. typhimurium A1-R-GFP isolated from the tumor, spleen and liver at various time points on LB agar. 

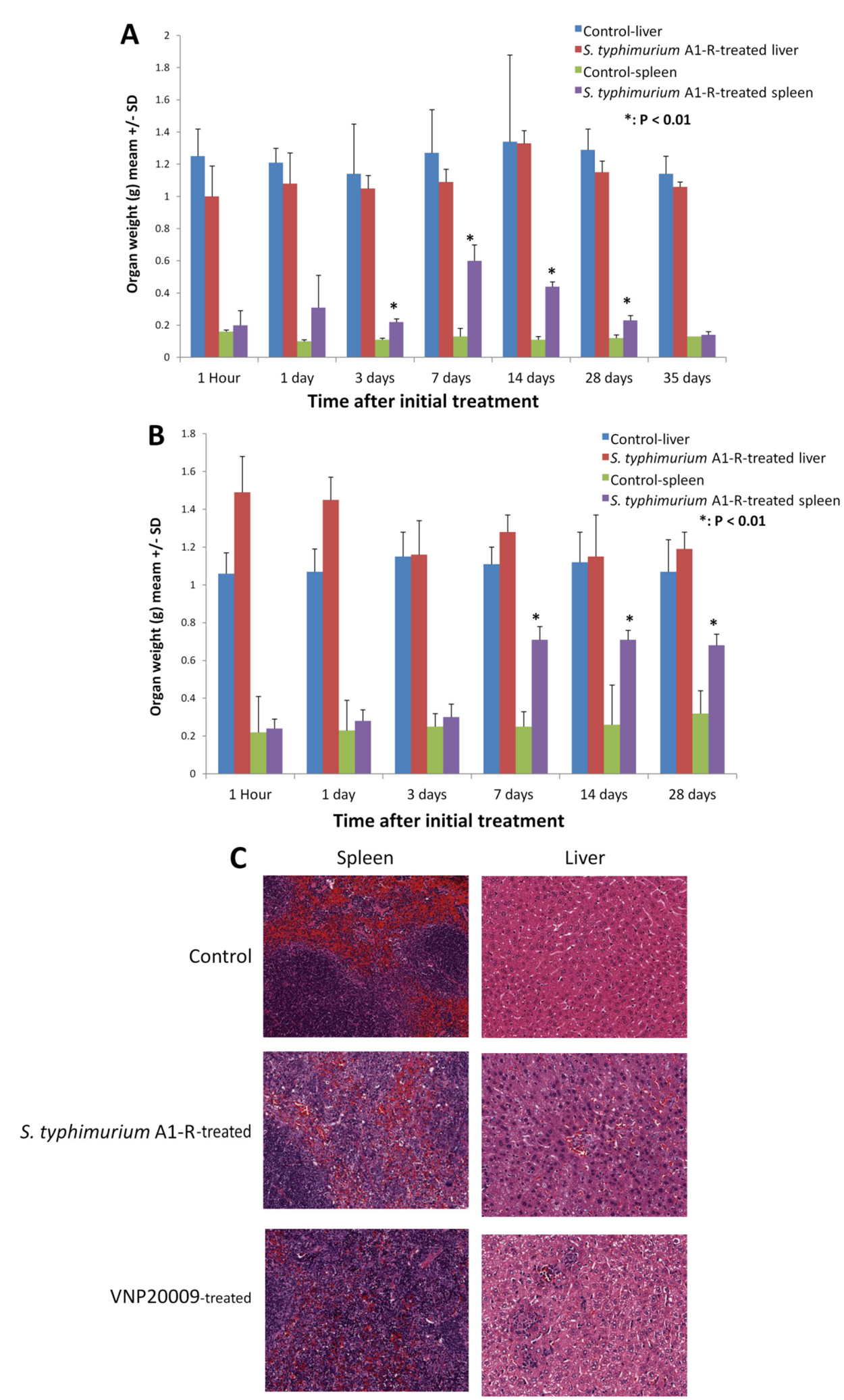

Figure 9: Toxicity of $S$. typhimurium A1-R on organ weight and S. typhimurium A1-R and S. typhimurium VNP20009 on organ histology. (A) Non-tumor-bearing BALB/c mice were treated with $5 \times 10^{5} \mathrm{CFU} / 100 \mu \mathrm{lBS} /$ mouse. Liver and spleen were removed, collected and weighed at different time points indicated above. $\mathrm{N}=6$ at each time point. (B) BALB/c mice bearing CT26 tumors with a tumor volume of $\left(100 \mathrm{~mm}^{3}\right)$ were treated with $5 \times 10^{5} \mathrm{CFU}$ S. typhimurium A1-R $100 \mu 1 \mathrm{PBS} /$ mouse. Liver and spleen were removed, collected and weighed at different time points indicated above. $\mathrm{N}=6$. (C) Hematoxylin and eosin (H\&E)-stained sections of spleens and livers of control, S. typhimurium A1-R-treated and VNP20009-treated non-tumor-bearing mice. 
not arrest tumor growth (Figure 10A). VNP20009 at $1 \times$ $10^{6} \mathrm{CFU}$ caused extensive mouse body weight loss, unlike the effective $5 \times 10^{5} \mathrm{CFU}$ dose of $S$. typhimurium A1-R (Figure 4).

Tumor weight was measured on day $19 . S$. typhimurium A1-R at $2.5 \times 10^{5} \mathrm{CFU}(\mathrm{p}<0.05)$ and $5 \times 10^{5}$ CFU $(\mathrm{p}<0.01)$ decreased tumor weight. VNP20009 at $1 \times$ $10^{6} \mathrm{CFU}$ inhibited tumor weight $(\mathrm{p}<0.05)$, but VNP20009 at $5 \times 10^{5} \mathrm{CFU}$ did not inhibit tumor weight (Figure 10B). VNP20009 at $1 \times 10^{6} \mathrm{CFU}$ caused severed body weight loss, as mentioned above (Figure 4). Both S. typhimurium A1-R and VNP20009, treated tumor contained viable nuclei, small areas of necrosis, with accompanying acute inflammation.

Previously-developed concepts and strategies of highly-selective tumor targeting can take advantage of molecular targeting of tumors, including tissue-selective therapy which focuses on unique differences between normal and tumor tissues [33-38].
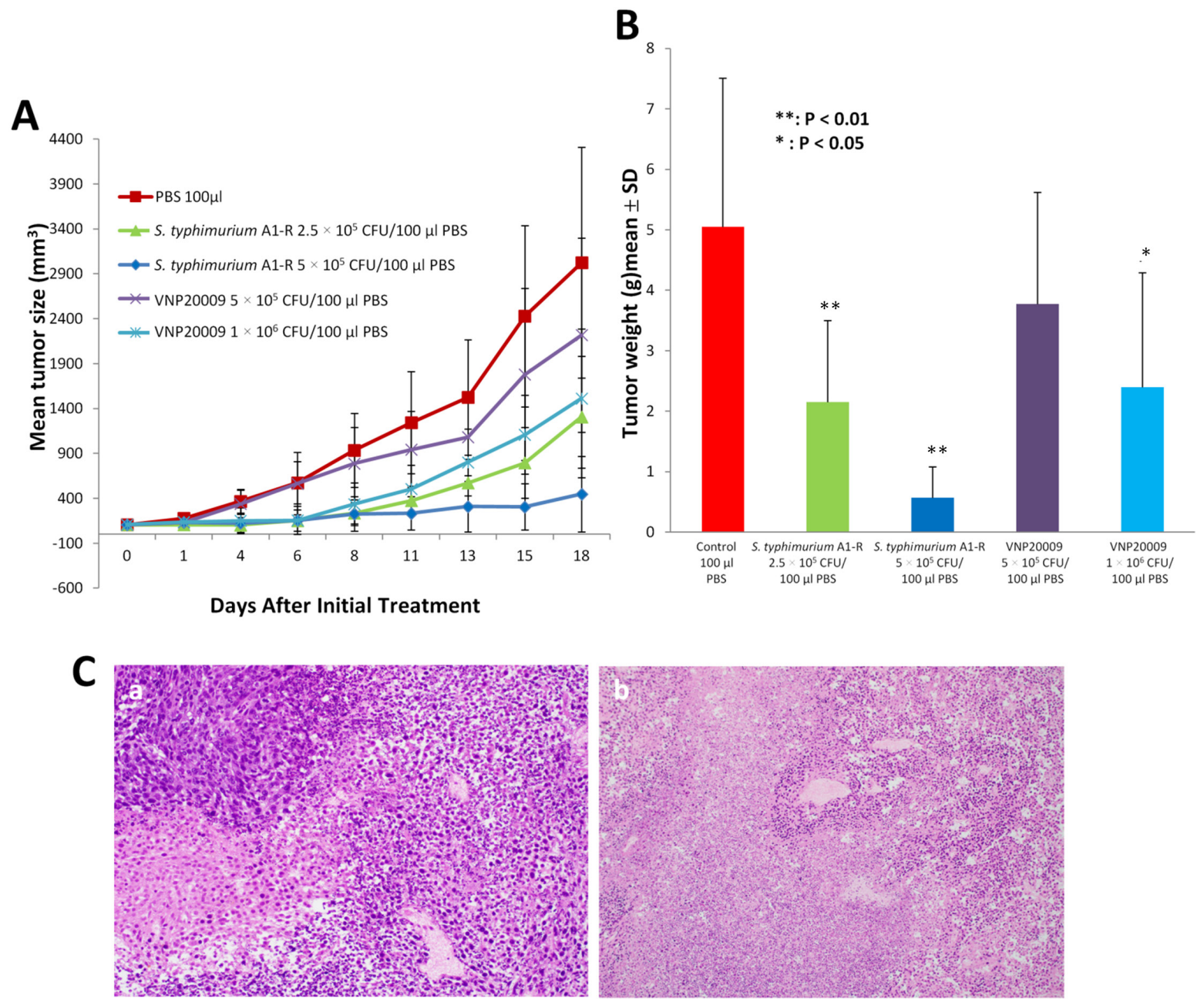

Figure 10: Antitumor efficacy of $\boldsymbol{S}$. typhimurium and VNP20009. CT26 cells $\left(2 \times 10^{6} / 100 \mu 1 /\right.$ mouse $)$ were injected into the right flank of BALB/c mice. When the average tumor volume reached approximately $100 \mathrm{~mm}^{3}$, S. typhimurium A1-R $\left(2.5\right.$ or $5 \times 10^{5}$ $\mathrm{CFU})$ or VNP20009 (5 or $\left.10 \times 10^{5} \mathrm{CFU}\right)$ were injected into the tail vein once a week for three times. Primary tumor sizes were measured with a caliper. (A) Tumor growth curves comparing $S$. typhimurium A1-R or $S$. typhimurium VNP at both doses. (B) Tumor weight in $S$. typhimurium A1-R- and S. typhimurium VNP20009-treated mice, compared to control mice $(* \mathrm{p}<0.05 ; * * \mathrm{p}<0.01)$ at day 19 after treatment. $\mathrm{n}$ $=5$ mice for each group. (C) Tumor histology shown in hematoxylin and eosin (H\&E)-stained sections. (a) Tumor treated with VNP20009; (b) tumor treated with S. typhimurium A1-R. 


\section{MATERIALS AND METHODS}

\section{Cell lines and other reagents}

Murine CT26 colon cancer cells were obtained from ATCC (The American Type Culture Collection) and grown in RPMI 1640 Medium (Invitrogen, Carlsbad, $\mathrm{CA}$ ) supplemented with $10 \%$ fetal bovine serum (FBS; HyClone, Logan City, UT) at $37^{\circ} \mathrm{C}$ with $5 \% \mathrm{CO}_{2}$.

\section{Mice}

Athymic $n u / n u$ nude mice (AntiCancer Inc., San Diego, CA), 4-6 weeks old, were used in this study. Animals were housed in a barrier facility on a high efficacy particulate arrestance (HEPA)-filtered rack under standard conditions of 12-hour light/dark cycles. The animals were fed an autoclaved laboratory rodent diet. All mouse surgical procedures and imaging were performed with the animals anesthetized by subcutaneous injection of a ketamine mixture $(0.02 \mathrm{ml}$ solution of $20 \mathrm{mg} / \mathrm{kg}$ ketamine, $15.2 \mathrm{mg} / \mathrm{kg}$ xylazine, and $0.48 \mathrm{mg} / \mathrm{kg}$ acepromazine maleate). The response of animals during surgery was monitored to ensure adequate depth of anesthesia. The animals were observed on a daily basis and humanely sacrificed by $\mathrm{CO}_{2}$ inhalation if they met the following humane endpoint criteria: severe tumor burden (more than 20 $\mathrm{mm}$ in diameter), prostration, significant body weight loss, difficulty breathing, rotational motion and body temperature drop. All animal studies were conducted in accordance with the principles and procedures outlined in the National Institutes of Health Guide for the Care and Use of Animals under Assurance Number A3873-1.

\section{Preparation of $S$. typhimurium A1-R}

GFP-expressing S. typhimurium A1-R bacteria (AntiCancer Inc.,) were grown overnight on LB medium (Fisher Sci., Hanover Park, IL, USA) and then diluted 1:10 in LB medium. Bacteria were harvested at latelog phase, washed with PBS, and then diluted in PBS $[8,11,12]$.

\section{Comparison of $\mathrm{OD}_{600}$ and colony counting to quantify bacteria}

GFP-expressing S. typhimurium A1-R were grown overnight in LB medium and then diluted 1:10 in LB medium. Bacteria were harvested at late-log phase, washed with PBS, and then serial diluted 10-fold for six times in PBS. $\mathrm{OD}_{600}$ measurements were performed on a spectrophotometer. Dilutions of bacteria were plated on LB agar and incubated at $37^{\circ} \mathrm{C}$ overnight. Colonies were counted under fluorescence microscopy to determine colonr forming units $(\mathrm{CFU} / \mathrm{ml})$ at each time point.

\section{Tumor inoculation}

Murine CT26 colon cancer cells $\left(2 \times 10^{6}\right)$ were injected subcutaneously into the right flank of BALB/c mice. Tumor volume was calculated as length $\times$ width $^{2}$ $\times 0.5$. In general, 10-14 days were required for tumors to reach the target size of $100 \mathrm{~mm}^{3}$ for treatment initation.

\section{Dose-tolerance experiments}

The dose-tolerance relationship was examined in $\mathrm{BALB} / \mathrm{c}$ mice for a single bolus or multiple doses once weekly for 3 consecutive weeks of S. typhimurium A1-R or VNP20009. Animal weights were compared with day 0 (first day of treatment administration) to determine percentage weight change. Mice were sacrificed at either $25 \%$ weight loss from day 0 or at the end of the observation period, which ever came first.

After administration of $S$. typhimurium A1-R or VNP20009 or control treatments, mice were closely monitored and weighed daily for 8 days, then at day 10 and 12 , and twice weekly until the end of the observation period. At this stage, the animals were euthanized by $\mathrm{CO}_{2}$ inhalation.

\section{Biodistribution of S. typhimurium A1-R-GFP}

At various time points after injection of $S$. typhimurium $\mathrm{A} 1-\mathrm{R}$, mice were sacrificed by $\mathrm{CO}_{2}$ narcosis at $1 \mathrm{~h}, 1$ day, 3 days, 7 days, 14 days and 28 days postinjection, and their blood $(0.1 \mathrm{ml})$, brain, heart, lungs, liver, spleen, kidneys, muscle, bone, small and large intestines, and tumor were harvested. Tissues were removed, weighed, and homogenized in phosphate buffered saline (PBS), at $2 \mathrm{ml}$ per $200 \mathrm{mg}$ of tissue using an homogenizer (Fisher Scientific, USA) at a speed of $\sim 24,000 \mathrm{rpm}$ for 30$60 \mathrm{~s}$. The resulting suspension was serial diluted by $10 \times$ dilutions in PBS and carefully spread onto LB agar. Blood was obtained from intracardiac puncture and mixed with 9 volumes of PBS, after which a $100 \mu$ suspension was spread on LB agar plates. LB agar plates were incubated for $18 \mathrm{~h}$ at $37^{\circ} \mathrm{C}$. Following incubation, plates were removed from the incubator and colonies were counted. At least three mice were used for each time point. $S$. typhimurium A1-R-GFP colonies were visualized with an Olympus OV100 Small Imaging System with a CCD camera [39].

\section{Histological analysis}

Fresh tumor and organ samples were fixed in $10 \%$ formalin and embedded in paraffin before sectioning and staining. Tissue sections $(5 \mu \mathrm{m})$ were deparaffinized in xylene and rehydrated in an ethanol series. Hematoxylin and eosin (H \&E) staining was performed according to standard protocols. Histological examination was performed with a BHS System Microscope (Olympus Corporation, Tokyo, 
Japan). Images were acquired with INFINITY ANALYZE software (Lumenera Corporation, Ottawa, Canada) [28].

\section{Anti-tumor efficacy}

$\mathrm{BALB} / \mathrm{c}$ mice bearing CT26 murine colon carcinoma xenografts were administered $S$. typhimurium A1-R or VNP20009 (i.v) with weekly doses indicated in Figure 10. Mice were monitored and weighed as described in the toxicity studies. Tumors were measured twice weekly using calipers along the $\mathrm{x}$ and $\mathrm{y}$ plane of the tumor. Tumor volume was determined using the formula volume $=\mathrm{ax}\left(\mathrm{b}^{2}\right) / 2$, where $\mathrm{a}$ is the largest diameter and $\mathrm{b}$ is the smallest diameter. Antitumor assessment of treatments was determined by reduction in tumor growth rate compared with controls.

\section{Statistical analysis}

All statistical analyses were performed using SYSTAT 12.0 (SYSTAT, Inc., Chicago, IL, USA). The experimental data are expressed as the mean \pm SD. The two-tailed Student's t-test was used for statistical analysis, with $\alpha$ equal to 0.05 . $\mathrm{P}<0.05$ was considered statistically significant.

\section{CONCLUSION}

S. typhimurium A1-R has a similar toxicity pattern as VNP20009 which was previously determined to be safe in a Phase I clinical trial. However, S. typhimurium A1-R had significantly greater tumor targeting and anti-tumor efficacy than VNP20009. The results of the present study, therefore, indicate the promising clinical potential of $S$. typhimurium A1-R.

Bacterial therapy offers many advantages over conventional chemotherapy, including, but not limited to tumor-targeting, ability to deliver therapeutic cargoes, does not depend entirely on the tumor vascular system to reach the tumor since bacteria are motile, can stimulate the immune system against the tumor, can serve as adjuvant treatment after surgery to eliminate residual disease and can enhance chemotherapy by decoying quiescent drugresistant cancer cells in tumors to attempt to cycle, thereby becoming sensitive to chemotherapy [4].

With regard to bacterial labeling, small molecular fluorescent probes or radionuclides may offer advantages over GFP to label $S$. typhimurium A1-R regarding translation to the clinic $[40,41]$. Whether $S$. typhimurium A1-R can pass the blood-brain barrier is still an open question. Although, S. typhimurium A1-R was found at early time-points in the brain in the present study, it is possible that bacteria were actually from brain blood vessels in which the bacteria have not passed to the brain tissue itself. On the other hand, S. typhimurium A1-R prevented brain metastasis in a breast cancer mouse model
[14]. It is not clear if the bacteria had to cross the bloodbrain barrier for this anti-brain-metastasis efficacy. Future experiments will address this point.

\section{DEDICATION}

This paper is dedicated to the memory of A. R. Moossa, M.D., and Sun Lee, M.D.

\section{CONFLICTS OF INTEREST}

The authors disclose no potential conflicts of interest.

\section{REFERENCES}

1. Wei MQ, Mengesha A, Good D, Anne J. Bacterial targeted tumour therapy-dawn of a new era. Cancer Lett. 2008; 259:16-27.

2. Morales A, Eidinger D, Bruce AW. Intracavitary Bacillus Calmette-Guerin in the treatment of superficial bladder tumors. J Urol. 2002; 167:891-893.

3. Kamat AM, Lamm DL. Intravesical therapy for bladder cancer. Urology. 2000; 55:161-168.

4. Hoffman RM, editor. Bacterial Therapy of Cancer: Methods and Protocols. Methods in Molecular Biology 1409. Walker, John M., series ed. Humana Press (Springer Science+Business Media New York). 2016.

5. Zhong Z, Kazmierczak RA, Dino A, Khreis R, Eisenstark A, Schatten H. Salmonella-host cell interactions, changes in host cell architecture, and destruction of prostate tumor cells with genetically altered Salmonella. Microsc Microanal. 2007; 13:372-383.

6. Leschner S, Weiss S. Salmonella-allies in the fight against cancer. J Mol Med. 2010; 88:763-773.

7. Clairmont $\mathrm{C}$, Lee $\mathrm{KC}$, Pike J, Ittensohn $\mathrm{M}$, Low $\mathrm{KB}$, Pawelek J, Bermudes D, Brecher SM, Margitich D, Turnier J, Li Z, Luo X, King I, et al. Biodistribution and genetic stability of the novel antitumor agent VNP20009, a genetically modified strain of Salmonella typhimurium. J Infect Dis. 2000; 181:1996-2002.

8. Zhao M, Yang M, Li XM, Jiang P, Baranov E, Li S, Xu M, Penman S, Hoffman RM. Tumor-targeting bacterial therapy with amino acid auxotrophs of GFP-expressing Salmonella typhimurium. Proc Natl Acad Sci U S A. 2005; 102:755-760.

9. Pawelek JM, Low KB, Bermudes D. Bacteria as tumortargeting vectors. Lancet Oncol. 2003; 4:548-556.

10. Toso JF, Gill VJ, Hwu P, Marincola FM, Restifo NP, Schwartzentruber DJ, Sherry RM, Topalian SL, Yang JC, Stock F, Freezer LJ, Morton KE, Seipp C, et al. Phase I study of the intravenous administration of attenuated Salmonella typhimurium to patients with metastatic melanoma. J Clin Oncol. 2002; 20:142-152. 
11. Zhao M, Geller J, Ma H, Yang M, Penman S, Hoffman RM. Monotherapy with a tumor-targeting mutant of Salmonella typhimurium cures orthotopic metastatic mouse models of human prostate cancer. Proc Natl Acad Sci U S A. 2007; 104:10170-10174.

12. Zhao M, Yang M, Ma H, Li X, Tan X, Li S, Yang Z, Hoffman RM. Targeted therapy with a Salmonella typhimurium leucine-arginine auxotroph cures orthotopic human breast tumors in nude mice. Cancer Res. 2006; 66:7647-7652.

13. Zhang Y, Tome Y, Suetsugu A, Zhang L, Zhang N, Hoffman RM, Zhao M. Determination of the optimal route of administration of Salmonella typhimurium A1-R to target breast cancer in nude mice. Anticancer Res. 2012; 32:2501-2508.

14. Zhang Y, Miwa S, Zhang N, Hoffman RM, Zhao M. Tumortargeting Salmonella typhimurium A1-R arrests growth of breast-cancer brain metastasis. Oncotarget. 2015; 6:26152622. doi: 10.18632/oncotarget.2811.

15. Uchugonova A, Zhao M, Zhang Y, Weinigel M, König K, Hoffman RM. Cancer-cell killing by engineered Salmonella imaged by multiphoton tomography in live mice. Anticancer Res. 2012; 32:4331-4339.

16. Liu F, Zhang L, Hoffman RM, Zhao M. Vessel destruction by tumor-targeting Salmonella typhimurium A1-R is enhanced by high tumor vascularity. Cell Cycle. 2010; 9:4518-4524.

17. Hiroshima Y, Zhang Y, Murakami T, Maawy AA, Miwa S, Yamamoto M, Yano S, Sato S, Momiyama M, Mori R, Matsuyama R, Chishima T, Tanaka K, et al. Efficacy of tumor-targeting Salmonella typhimurium A1-R in combination with anti-angiogenesis therapy on a pancreatic cancer patient-derived orthotopic xenograph (PDOX) and cell line mouse models. Oncotarget. 2014; 5:12346-12357. doi: 10.18632/oncotarget.2641.

18. Nagakura C, Hayashi K, Zhao M, Yamauchi K, Yamamoto N, Tsuchiya H, Tomita K, Bouvet M, Hoffman RM. Efficacy of a genetically-modified Salmonella typhimurium in an orthotopic human pancreatic cancer in nude mice. Anticancer Res. 2009; 29:1873-1878.

19. Yam C, Zhao M, Hayashi K, Ma H, Kishimoto H, McElroy M, Bouvet M, Hoffman RM. Monotherapy with a tumortargeting mutant of $S$. typhimurium inhibits liver metastasis in a mouse model of pancreatic cancer. J Surg Res. 2010; 164:248-255.

20. Hiroshima Y, Zhao M, Zhang Y, Maawy A, Hassanein MK, Uehara F, Miwa S, Yano S, Momiyama M, Suetsugu A, Chishima T, Tanaka K, Bouvet M, et al. Comparison of efficacy of Salmonella typhimurium A1-R and chemotherapy on stem-like and non-stem human pancreatic cancer cells. Cell Cycle. 2013; 12:2774-2780.

21. Hiroshima Y, Zhao M, Maawy A, Zhang Y, Katz MH, Fleming JB, Uehara F, Miwa S, Yano S, Momiyama M, Suetsugu A, Chishima T, Tanaka K, et al. Efficacy of Salmonella typhimurium A1-R versus chemotherapy on a pancreatic cancer patient-derived orthotopic xenograft (PDOX). J Cell Biochem. 2014; 115:1254-1261.

22. Matsumoto Y, Miwa S, Zhang Y, Hiroshima Y, Yano S, Uehara F, Yamamoto M, Toneri M, Bouvet M, Matsubara H, Hoffman RM, Zhao M. Efficacy of tumor-targeting Salmonella typhimurium A1-R on nude mouse models of metastatic and disseminated human ovarian cancer. J Cell Biochem. 2014; 115:1996-2003.

23. Matsumoto Y, Miwa S, Zhang Y, Zhao M, Yano S, Uehara F, Yamamoto M, Hiroshima Y, Toneri M, Bouvet M, Matsubara H, Tsuchiya H, Hoffman RM. Intraperitoneal administration of tumor-targeting Salmonella typhimurium A1-R inhibits disseminated human ovarian cancer and extends survival in nude mice. Oncotarget. 2015; 6:1136911377. doi: 10.18632/oncotarget.3607.

24. Yano S, Zhang Y, Zhao M, Hiroshima Y, Miwa S, Uehara F, Kishimoto H, Tazawa H, Bouvet M, Fujiwara T, Hoffman RM. Tumor-targeting Salmonella typhimurium A1-R decoys quiescent cancer cells to cycle as visualized by FUCCI imaging and become sensitive to chemotherapy. Cell Cycle. 2014; 13:3958-3963.

25. Hiroshima Y, Zhang Y, Zhao M, Zhang N, Murakami T, Maawy A, Mii S, Uehara F, Yamamoto M, Miwa S, Yano S, Momiyama M, Mori R, et al. Tumor-targeting Salmonella typhimurium A1-R in combination with Trastuzumab eradicates HER-2-positive cervical cancer cells in patientderived mouse models. PLoS One. 2015; 10:e120358.

26. Murakami T, DeLong J, Eilber FC, Zhao M, Zhang Y, Zhang N, Singh A, Russell T, Deng S, Reynoso J, Quan C, Hiroshima Y, Matsuyama R, et al. Tumor-targeting Salmonella typhimurium A1-R in combination with doxorubicin eradicate soft tissue sarcoma in a patientderived orthotopic xenograft (PDOX) model. Oncotarget. 2016; 7:12783-12790. doi: 10.18632/oncotarget.7226.

27. Kiyuna T, Murakami T, Tome Y, Kawaguchi K, Igarashi K, Zhang Y Zhao M, Li Y, Bouvet M, Kanaya F, Singh A, Dry S, Eilber FC, et al. High efficacy of tumor-targeting Salmonella typhimurium A1-R on a doxorubicin- and dactolisib-resistant follicular dendritic-cell sarcoma in a patient-derived orthotopic xenograft nude mouse model. Oncotarget. 2016; 7:33046-33054. doi: 10.18632/ oncotarget.8848.

28. Murakami T, Igarashi K, Kawaguchi K, Kiyuna T, Zhang Y, Zhao M, Hiroshima Y, Nelson SD, Dry SM, Li Y, Yanagawa J, Russell T, Federman N, et al. Tumor-targeting Salmonella typhimurium A1-R regresses an osteosarcoma in a patientderived xenograph model resistant to a molecular-targeting drug. Oncotarget. 2017; 8:8035-8042. doi: 10.18632/ oncotarget.14040.

29. Yamamoto M, Zhao M, Hiroshima Y, Zhang Y, Shurell E, Eilber F, C, Bouvet M, Noda M, Hoffman RM. Efficacy of tumor-targeting Salmonella typhimurium A1-R on a melanoma patient-derived orthotopic xenograft (PDOX) nude-mouse model. PLoS One. 2016; 11:e0160882. 
30. Kawaguchi K, Igarashi K, Murakami T, Chmiewloski B, Kiyuna T, Zhao M, Zhang Y, Singh A, Unno M, Nelson SD, Russell T, Dry SM, Li Y, et al. Tumor-targeting Salmonella typhimurium A1-R combined with Temozolomide regresses malignant melanoma with a BRAF-V600 mutation in a patientderived orthotopic xenograft (PDOX) model. Oncotarget. 2016; 7:85929-85936. doi: 10.18632/oncotarget.13231.

31. Kawaguchi K, Murakami T, Chmielowski B, Igarashi K, Kiyuna T, Unno M, Nelson SD, Russell TA, Dry SM, Li Y, Eilber FC, Hoffman RM. Vemurafenib-resistant BRAFV600E mutated melanoma is regressed by MEK targeting drug trametinib, but not cobimetinib in a patient-derived orthotopic xenograft (PDOX) mouse model. Oncotarget. 2016; 7:71737-71743. doi: 10.18632/oncotarget.12328.

32. Kawaguchi K, Igarashi K, Murakami T, Zhao M, Zhang Y, Chmielowski B, Kiyuna T, Nelson SD, Russell TA, Dry SM, Li Y, Unno M, Eilber FC, et al. Tumor-targeting Salmonella typhimurium A1-R sensitizes melanoma with a BRAF-V600E mutation to vemurafenib in a patientderived orthotopic xenograft (PDOX) nude mouse model. J Cell Biochem. 2017 Jan 20. doi: 10.1002/jcb.25886. [Epub ahead of print]

33. Blagosklonny MV. Matching targets for selective cancer therapy. Drug Discov Today. 2003; 8:1104-1107.

34. Blagosklonny MV. Teratogens as anti-cancer drugs. Cell Cycle. 2005; 4:1518-1521.

35. Blagosklonny MV. Treatment with inhibitors of caspases, that are substrates of drug transporters, selectively permits chemotherapy-induced apoptosis in multidrugresistant cells but protects normal cells. Leukemia 2001; 15:936-941.

36. Blagosklonny MV. Target for cancer therapy: proliferating cells or stem cells. Leukemia. 2006; 20:385-391.

37. Apontes $\mathrm{P}$, Leontieva OV, Demidenko ZN, Li F, Blagosklonny MV. Exploring long-term protection of normal human fibroblasts and epithelial cells from chemotherapy in cell culture. Oncotarget. 2011; 2:222233. doi: 10.18632/oncotarget.248.

38. Blagosklonny MV. Tissue-selective therapy of cancer. Br J Cancer. 2003; 89:1147-1151.

39. Yamauchi K, Yang M, Jiang P, Yamamoto N, Tsuchiya H, Tomita K, Moossa AR, Bouvet M, Hoffman RM. Development of real-time with subcellular dynamic multicolor imaging of cancer cell trafficking in live mice with a variable-magnification whole-mouse imaging system. Cancer Res. 2006; 66:4208-4214.

40. Kobayashi H, Longmire MR, Ogawa M, Choyke PL. Rational chemical design of the next generation of molecular imaging probes based on physics and biology: mixing modalities, colors and signals. Chem Soc Rev. 2011; 40:4626-4648.

41. Kobayashi H, Ogawa M, Alford R, Choyke PL, Urano Y. New strategies for fluorescent probe design in medical diagnostic imaging. Chen Rev. 2010; 110:2620-2640. 